\title{
ASSESSMENT OF THE PRECISION OF A SMART-PHONE POLE PHOTOGRAMMETRY FOR A SECOND-ORDER CLIFF SURFACE DEFORMATION STUDIES
}

\author{
M.A. Eboigbe'1, D. B. Kidner ${ }^{2}$ \\ ${ }^{1}$ Ph.D. Student, University of South Wales, Faculty of Engineering and Computing, UK. mitchell.eboigbe@ southwalees.ac.uk \\ ${ }^{2}$ Reader, University of South Wales, Faculty of Engineering and Computing, UK david.kidner@ southwales.ac.uk.
}

KEY WORDS: Pole Photogrammetry, Coastal Cliff, Deformation Study

\begin{abstract}
:
Coastal cliff is almost a vertical elongated structure with a wave-cut notch and a landslip. Cliffs are geological formations with an almost unpredictable and unstoppable detachment between constitutes formations. Due to health, safety, environmental, and military restrictions, there are more regulations and restrictions on the use of drones. There are also the issues of portability and high cost for the purchase of hybrid drones and Terrestrial Laser Scanners (TLS). These negate the regular monitoring of the coastal cliff. This research develops a rapid, low-cost, and precise digital photogrammetry methodology for the continuous monitoring of the cliff by using the pole as the platform and a mobile phone as a sensor. The most practical vertical camera angle, image overlaps, survey distance to the cliff, and realistic time range for surveys are all determined from the basic surveying principles. Precise geometrically related point clouds generated are with or without the Global Navigation Satellite Systems (GNSS). The standard deviation for "alignment and surface deviation" at every point on each point cloud is $\pm 0.05 \mathrm{~m}$ in the Northing and $\pm 0.12 \mathrm{~m}$ on the Easting's for the self-calibrated digital camera and without the use of GNSS control points. With the GNSS controls, the maximum deviation in the $\mathrm{XYZ}$ coordinates is $\pm 5 \mathrm{~cm}$. Change analysis performed identifies areas of cut, fill, and the segment of threats in all point clouds. The photogrammetric technique developed is very cheap, simple, and reliable with minimum labor. The results obtained indicate the applicability of this methodology for second-order cliff Deformation study.
\end{abstract}

\section{INTRODUCTION}

With drones, pre-programmed flight routes are automatically set at the best angle that captures images on a regular grid pattern and flight speed (Varela et al, 2019; Colomina and Molina, 2014; Perez-Alberti and Trenhaile, 2014). To survey the cliff surface on a manual flight mission with the drone requires great experience to obtain an optimal flight mission and generate orthometric and digital models required for mapping purposes (Mancini et al, 2017). Digital images acquired arbitrarily from the ground stations to survey the cliff would be difficult to generate a complete overlapping stereo oriented model for consistent and precise 3D models and 3D maps except as a rare 'accidental success'.

The use of poles and masks as platforms would require ground-based camera locations. The distance between these ground-based stations and the cliff surface (L) is as the height $(\mathrm{H})$ above the ground in aerial surveys. Like the traditional aerial surveys, camera-based stations on the ground would require very careful and systematic planning to achieve the best Ground Sampling Distance (GSD) (Huang et al, 2015), sensor stability (Roncella et al, 2014), overlap and reduce the effects of random errors and accumulation of systematic errors (Aber and Babb, 2018; James and Robson, 2014). The length between the baseline and cliff $(\mathrm{L})$, the linear dimension of the pixel (px), and the camera lens' focal length (f) will determine GSD accuracies as camera pixels will be mapped to the cliff surface

Geological formations of limestone, sandstone, chalk, rock shelters, and granite characterize the cliff surface (Terefenko et al, 2018). Several crests of waves on the cliff surface depend on the formation of the sections on the cliff and such irregular spectral frequencies cause both low and high contrast across the electromagnetic spectrum (Young et al, 2016). Digital photogrammetry is more challenging when using lowquality complementary metal-oxide-semiconductor CMOS or the Charge-coupled devices CCD image sensors (Dai et al, 2014) as with this research. The best pattern of forward and side overlap and the distance between the camera's stations to the cliff surface is; therefore, determine to generate the best spatial and spectral resolutions for deformation analysis.

Due to the height of the coastal cliff and considering the very short distance between the camera location and the cliff surface, there must be careful considerations on the angle of the camera, camera calibration, stabilization, and sensor orientation to overcome yaw variation, rolls variation, altitude variation, perspective variation, barrel, and pincushion. The accuracies on the computation of the exterior orientation parameters by the BBA using the Integrated Sensor Orientation (ISO) is usually affected by both the satellite geometry and the lock on the available GNSS constellation (Rau et al, 2011). GNSS radio signals delays are mainly by the free electrons in the ionosphere and by other atmospheric conditions in the troposphere (Zhang et al, 2019). The Earth rotation induces charged particles into the magnetic field line in the ionosphere and capable of distorting the propagation of radio waves signal (Constable, 2016). Ionospheric propagation delays are of higher magnitude than the tropospheric delays and largely degrade the accuracies in single-frequency GNSS receivers' especially inbuilt GNSS sensors on smartphones and other inexpensive digital cameras (Karaim et al, 2018). Considerations are in place also to obtain the best time-lapse for satellite geometry when mapping the cliff surface using the pole photogrammetry due to drift in the GPS/INS low-quality digital camera/GPS sensor (Masiero et al, 2017).

The coastal cliff undergoes regular physical and chemical weathering processes (Earlie et al, 2017 and Sciarra et al, 2014) 
as well as seawater crashing against the surface (Earlie et al, 2017). Cliff surface weathering causes an almost unpredictable and unstoppable detachment between constitutes formations and eventual collapse (Singh et al, 2016). The coastal cliffs are therefore asymmetrical with complex surface discontinuities (Letortu et al, 2018; Westoby et al, 2018; Ruzic et al, 2015; Galea et al, 2014; Somma et al, 2015 and Sciarra et al, 2014). It is difficult therefore to establish temporary/permanent control points on the cliff surface. The establishment of GNSS points close to the cliff at either the top or toe in some coastal area is practically difficult due to such high-volume sea wave and cliff surface erosion (Earlie et al, 2017). This is the situation in Penarth (study location) very peculiar with the Bristol Channel and the regular cliff face collapse. GNSS equipment is expensive to buy/ borrow and may not be available in most situations. It is imperative to develop a cost-effective and precise methodology using the Structure from Motion SFM derived point cloud for coastal cliff geotechnical and structural change detection analysis. For existing close-range digital photogrammetry techniques, consistent and accurate time-series orthomosaics and digital models for environmental monitoring are feasible on the availability of GNSS points (Ruzgiene et al, 2015 and Turner et al, 2015). The method developed is a simple and straightforward photogrammetry technique for consistent and precise evaluation of the cliff surface with or without the GNSS controls.

\section{METHODOLOGY}

\subsection{Determine an Appropriate Vertical Camera Angle to the Cliff}

The basic transformational matrixes of each grid cell relate every pixel location in the image relative to the cliff surface elevation. The digital camera self-calibration solution includes the direct computation for the interior and exterior parameters, which allows the transformation from 3D coordinate $(\mathrm{X}, \mathrm{Y}, \mathrm{Z})$ of the ground point to a $2 \mathrm{D}$ coordinate $(\mathrm{u}, \mathrm{v})$ of the image in pixels. The basic perspective projection centre of the perspective lens cameras relates the scene properties as pixels where the origin is the camera centre defined by its position and orientation.

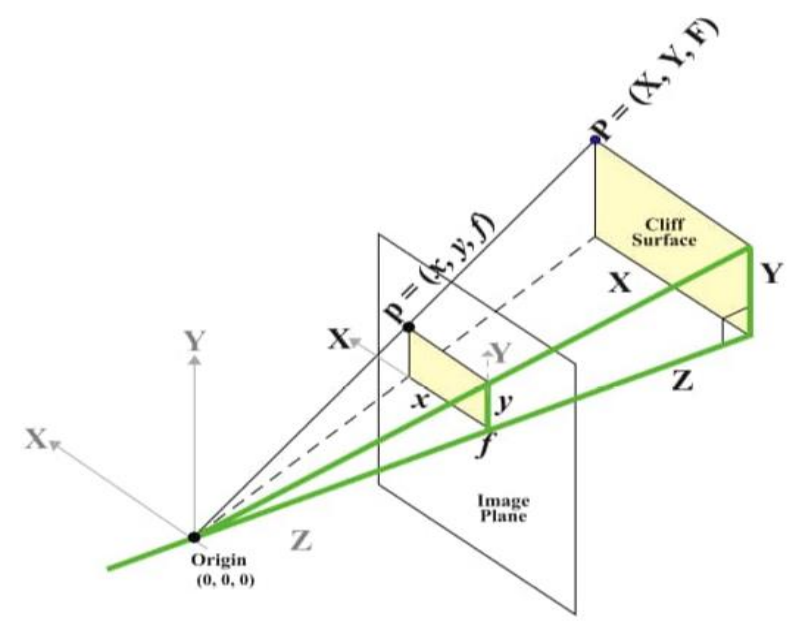

Figure 1. Perspective Projection

The origin and geometrical sequence between each grid cell determine the transformation matrix of orientation parameters that form the image of the object by relating the scene properties as pixels (Liu et al, 2016). The origin is the camera centre defined by its position and orientation (Xu et al, 2017).

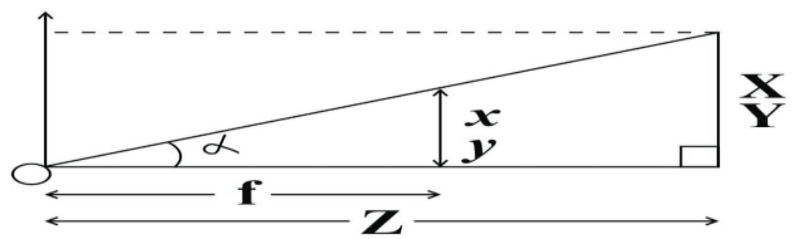

Figure 2. Central Projection

$\mathrm{x}=f_{\bar{Z}}^{X}$ and $\mathrm{y}=f \frac{\mathscr{Y}}{Z}$

Digital photos acquired from off-nadir angle geometry will generate denser tie-points and create a better model for the cliff surface compared with photos acquired from the nadir positions (Nesbit and Hugenholtz, 2019; Juad et al, 2016; Mancini et al, 2017). The reduction of systematic errors is from the reduction of gaps between adjoining digital images on the cliff surface geometry that is vertically irregular (Nesbit and Hugenholtz, 2019). This section experiment on an appropriate vertical camera angle that would be suitable to;

a) High overlapping images that can generate a dense point cloud

b) Obtain pixel texture accuracies for cliff surfaces

c) Survey the entire height of the cliff with geometric accuracies

This practical solution is reliant on the cliff surface characteristics, the resolution of the digital camera, and the pole as a platform using the perpendicular orientation geometry as shown below.

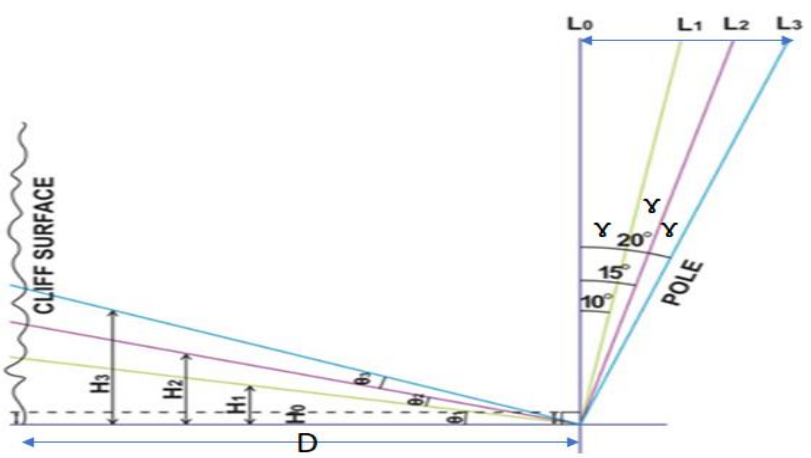

Figure 3. Viewing and Orientation Geometry to the Cliff

$\Theta=$ Observing angle

$\gamma=$ Vertical camera angle

$\mathrm{H}=$ Height of the section on the cliff

$\mathrm{D}=$ Ground distance

$\mathrm{Pr}=$ Pixel size perpendicular to the vertical camera angle

$\mathrm{P} \Theta=$ Angular segment on the cliff surface. $\tan \Theta=\frac{\mathrm{H}}{\mathrm{D}}=$

At $\mathrm{L}$, the height of the cliff will be $\mathrm{H}$ while $\mathrm{Pr}$ is smaller provided every other photogrammetric constraint such as clouds, haze, and poor image overlap are minimal. This research experiments on the perpendicular orientation geometry using four different surveys at four different vertical cameras angle to the cliff section measuring 27 meters in length. The outcome is figure 4 below. 

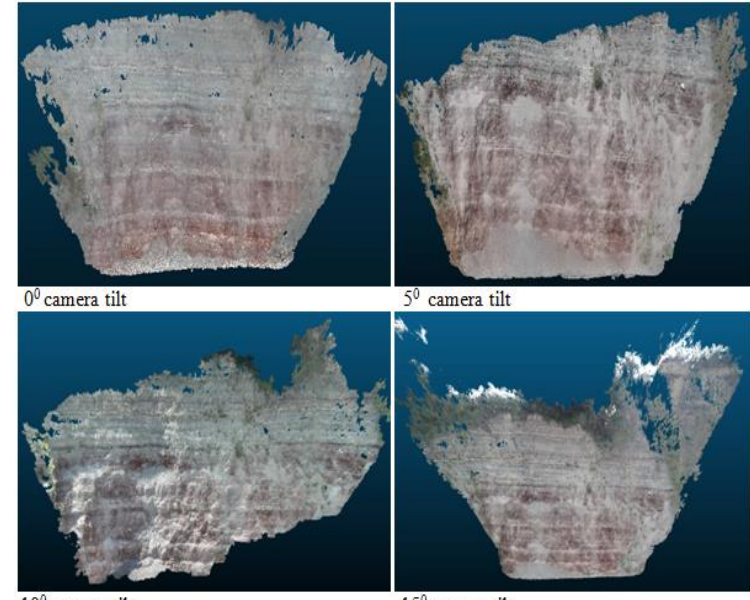
$5^{0}$ camera tilt

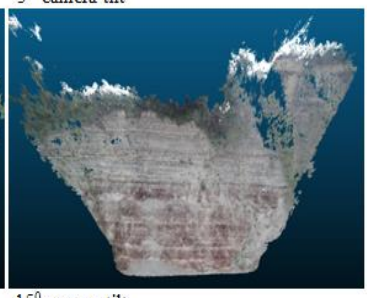

$10^{0}$ camera tilt

$15^{0}$ camera tilt

Figure 4. Dense Point Cloud obtained from Four Vertical Camera Angle

\subsection{Determining the Best Distance between the Cliff Surface and the Base Line}

In close-range photogrammetry, the digital camera could be as close as a few centimeters to the object being monitored which favorably improves on the image resolution (Westoby et al, 2015). However, when monitoring an unstable cliff like the Penarth, 1-2 meters could be dangerous and unfavorable to the field of view (FOV) with constraints on the orientation angle of the digital camera. The best practice would be a trade-off between the distance to the cliff surface, the FOV, and the cliff height. The camera distance to the cliff surface determines the GSD. Shorter distances between the camera and the cliff will turn out into a smaller GSD provided every other photogrammetric constraint is at minimal while larger distances could amount to greater GSD especially with the use of low/medium resolution digital cameras. Smaller GSD will have a higher spatial resolution. The GSD should be at least half of the smallest object on the ground for measurement (Tziavou et al, 2018).

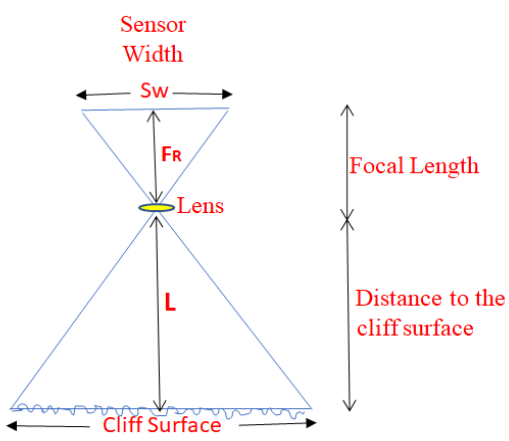

Figure 5 Sensor Width Relative to the FOV

$$
\begin{aligned}
& \text { GSD }=\frac{\mathrm{L} * p x}{f} \\
& \mathrm{~L}=\frac{\mathrm{GSD} * F}{P X}
\end{aligned}
$$

Most times the pixels, when projected onto the ground, will not be squared perfectly. The GSD would then be computed for in terms of sensor width and sensor height.
GSD $=$ Ground Sampling Distance

$\mathrm{L}=$ the length between the baseline and cliff

$f=$ the focal length of the digital camera

$p x=$ the pixel linear dimension

To determine approximately the GSD For a distance of 3 meters between the baseline and the cliff, using the Samsung (SMG850F Camera);

The focal length of the Samsung SM-G850F camera $=1.2 \mathrm{~mm}$

Pixel height $=1920$

Pixel width $=1080$

Approximate sensor width $=9.61923 \mathrm{~mm}$

Approximate sensor height $=5.410082 \mathrm{~mm}$

$$
\begin{array}{rlrl}
\text { Width }= & \frac{3 * 5.410821}{1.2 * 1080} \\
& \mathbf{1 . 2 5} \mathbf{c m} / \mathbf{p x} & \text { Height } & =\frac{3 * 9.619238}{1.2 * 1920} \\
& =\mathbf{1 . 2 5} \mathbf{c m} / \mathbf{p x} .
\end{array}
$$

To derive a baseline that is photogrammetric stable between the camera position and the cliff, the cliff was surveyed three different times at three different baselines. The section of the cliff monitored is 27 meters in length. The Samsung Alpha phone SM-G850F Front Camera of 2.1 megapixels was on an 11 meters pole for these surveys. The outcome of each survey is the table I below

\begin{tabular}{|c|c|c|c|c|c|}
\hline $\begin{array}{l}\text { L } \\
(\mathrm{m})\end{array}$ & $\begin{array}{c}\text { No. of } \\
\text { Photos }\end{array}$ & $\begin{array}{c}\text { Avera } \\
\text { ge } \\
\text { GSD } \\
(\mathrm{cm})\end{array}$ & $\begin{array}{c}\text { 2D Key } \\
\text { points } \\
\text { extracted } \\
\text { for BBA }\end{array}$ & $\begin{array}{c}\text { 3D Key } \\
\text { points } \\
\text { for BBA }\end{array}$ & $\begin{array}{c}\text { Mean } \\
\text { projection } \\
\text { errors in } \\
\text { pixel }\end{array}$ \\
\hline $\mathbf{3}$ & 169 & 1.68 & 3782815 & 1303566 & 0.254 \\
\hline $\mathbf{5}$ & 169 & 0.73 & 3174090 & 786342 & 0.268 \\
\hline $\mathbf{1 0}$ & 169 & 2.05 & 3958836 & 838557 & 0.309 \\
\hline
\end{tabular}

Table 1. The outcome of three Different Surveys to determine a Practical Base Line to the Cliff

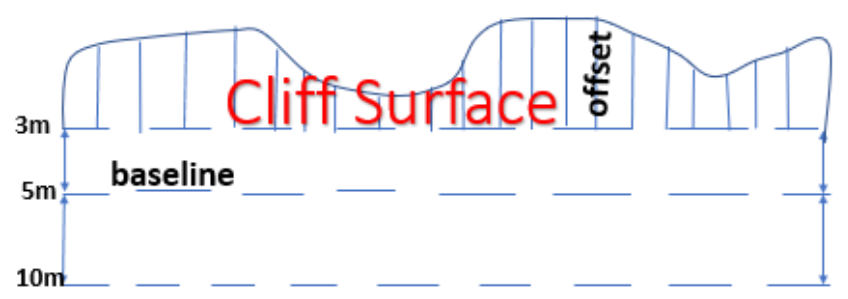

Figure 6. The Three Different Baseline Distances from the Cliff

\subsection{Determine a Practicable forward and side overlap}

The terrain topography and purpose of the photogrammetric project determine the choice and percentage of overlap (Pepe et al, 2018). Recommendations, however, are for a regular grid pattern (Carter et al, 2019) of $60 \%$ side overlap and $80 \%$ forward overlap (Cwiakala et al, 2018; Turner et al, 2015; Colomina and Molina, 2014). To generate tie-points with maximum density, every point in the object space should be in a minimum of 4-5 images (Ruzgiene et al, 2015). 


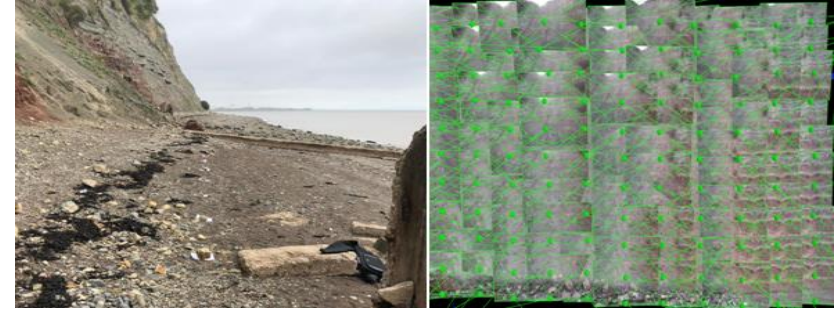

Figure 7. Degree of Overlap from Marked Points on the Ground

Poles stations were at every $1.65 \mathrm{~m}$ marked on the ground with a white paper as shown on the Left-Hand Side LHS of fig. 4.9. The painters' pole used is $11 \mathrm{~m}$ long and segmented at every $1 \mathrm{~m}$. The average percentage of overlap is $55 \%$ horizontal and $58 \%$ vertical. Figure 5 below illustrates the number of overlapping images.

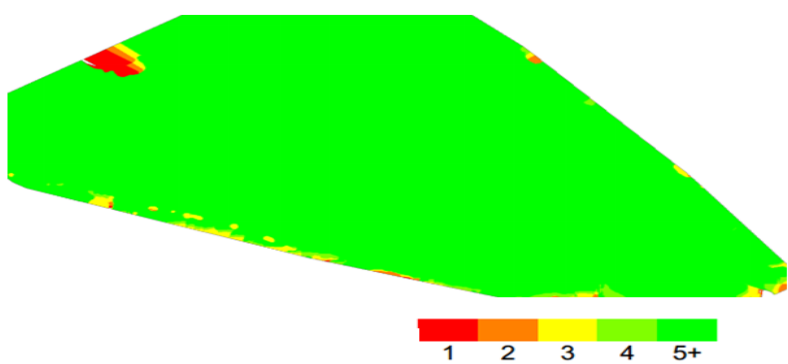

Figure 8. Number of Overlapping Images

\subsection{Determine an Appropriate Time-Lapse for Surveying the Cliff with the Pole Using the Integrated Sensor Orientation (ISO)}

In the ISO, the computation of the Bundle Block Adjustment BBA is by the use of the inbuilt GNSS sensors and the compact Micro-Electro-Mechanical Systems Inertial Measurement Unit (MEMS IMU) without GNSS controls and pre-defined tie points (Pepe et al, 2018 and Benassi et al, 2017). Although the ISO is straight to use, the cheap miniature sensors with cheap inbuilt GPS are downgraded easily especially in very dynamic environments (Benassi et al, 2017). The accelerometer and gyros of the MEMS-IMU are also flexible and can easily drift during use due to their microstructure compartments. The tropospheric signal delays characterized by pressure, temperature, and water vapour are relative to geographical elevation ( $\mathrm{Yu}$ et al, 2018 and Zhu et al, 2017) with water vapour predominant in the coastal areas. The accuracies of close-range photogrammetric surveys will improve on favourable atmospheric conditions (Pepe et al, 2018) likely on lesser time durations.

Inexpensive GNSS sensors would be difficult to generate consistent and reliable dense point cloud due to inherent anomalies in the Scale Invariant Feature Transformations (SIFT) (Qu et al, 2018) which detects and extract the local features in the corresponding digital images. It would be difficult then to minimize errors from transformation and misalignments which ideally are reduced by the GNSS controls and tie points as with the Integrated Sensor Orientation (ISO) and GNSS-supported Aerial Triangulation (GNSS-AT) in digital photogrammetry (Benassi et al, 2017). To balance off systematic and random errors from the ionospheric and tropospheric delays, drifting, and downgrading of the inbuilt GPS, this research relies on the systematic field procedure(s) developed in the foregoing sections. The aim is to obtain the maximum number of images that would be calibrated for SIFT. The cliff surface was surveyed at different time-range to establish the level-oftolerance of the inexpensive Samsung SM-G850F MEMSIMU/inbuilt GNSS sensors on favourable atmospheric and illumination (shadow cast) conditions.

\begin{tabular}{|c|c|c|c|c|c|}
\hline & $\begin{array}{c}\text { Time } \\
\text { Range } \\
\text { Minutes }\end{array}$ & $\begin{array}{c}\text { No. of } \\
\text { images }\end{array}$ & $\begin{array}{c}\text { \% of } \\
\text { calibrated } \\
\text { images }\end{array}$ & $\begin{array}{c}\text { Using the } \\
\text { New field } \\
\text { Method }\end{array}$ & $\begin{array}{c}\text { Point } \\
\text { cloud }\end{array}$ \\
\hline a & $00: 30: 03$ & 86 & 100 & yes & $\begin{array}{c}\text { Single } \\
\text { block } \\
\text { mosaic }\end{array}$ \\
\hline b & $00: 59: 28$ & 187 & 100 & yes & $\begin{array}{c}\text { Single } \\
\text { block } \\
\text { mosaic }\end{array}$ \\
\hline c & $01:$ & 198 & 100 & yes & $\begin{array}{c}\text { Single } \\
\text { block } \\
\text { mosaic }\end{array}$ \\
\hline d & $02: 16: 31$ & 490 & 98 & $80 \%$ & $\begin{array}{c}\text { Multiple } \\
\text { block } \\
\text { mosaic }\end{array}$ \\
\hline e & $02: 52: 50$ & 377 & 100 & yes & $\begin{array}{c}\text { Single } \\
\text { block } \\
\text { mosaic }\end{array}$ \\
\hline f & $03: 05: 36$ & 517 & 99 & yes & $\begin{array}{c}\text { Single } \\
\text { block } \\
\text { mosaic }\end{array}$ \\
\hline
\end{tabular}

Table 2. Time Range to Determine the Level-of Tolerance of the Miniature Sensors

While surveys executed at lesser times will easily overcome systematic and random errors, good overlap, and a regular survey grid pattern can compensate for errors. The pattern for capturing images in $\mathbf{d}$ on table 2.was a horizontal survey grid with more images taken after the main survey to verify the effect of drifting. The dense point cloud from survey $\mathbf{d}$ in table 2. is downgraded into multiple block mosaics as shown below.

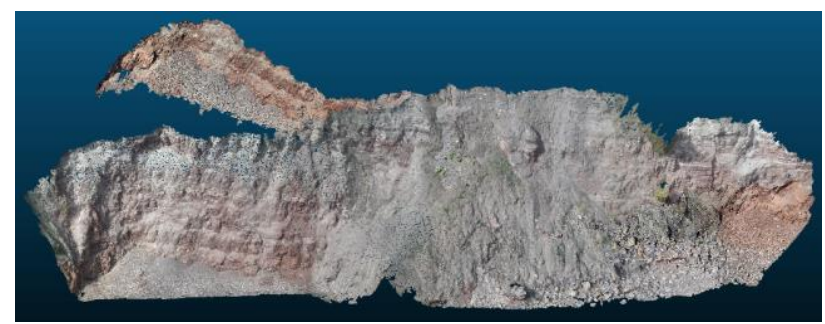

Figure 8. Multiple Block Point Cloud Showing the Effect of Drifting on the Inexpensive GNSS Sensors

\section{EVALUATING THE GEOMETRIC PRECISIONS OF THE POLE SURVEY FOR CLIFF SURFACE DEFORMATION STUDIES}

The different point clouds generated should be geometrically precise for evaluative purposes (Kromer et al, 2015). Comparisons were on four different point clouds obtained from four weekly surveys to determine the consistencies and reliability of the new pole mapping field sequence. 


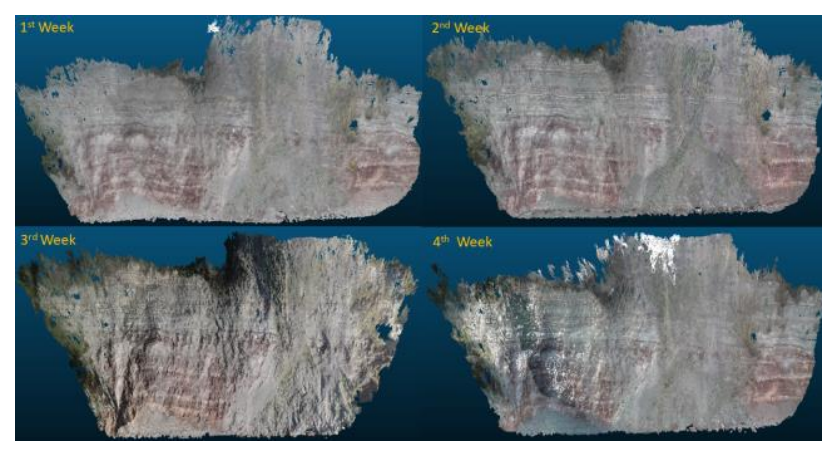

Figure 9. Dense Point Clouds from four Weekly Surveys

\begin{tabular}{|l|c|c|c|c|}
\hline & $\mathbf{1}^{\text {st }}$ Survey & $\begin{array}{c}\mathbf{2}^{\text {nd }} \\
\text { Survey }\end{array}$ & $\begin{array}{c}\mathbf{3}^{\text {rd }} \\
\text { Survey }\end{array}$ & $\begin{array}{c}\mathbf{4}^{\text {th }} \\
\text { Survey }\end{array}$ \\
\hline $\begin{array}{l}\text { Date } \\
\text { of } \\
\text { survey }\end{array}$ & $02-10-18$ & $11-10-18$ & $22-10-18$ & $30-10-$ \\
\hline $\begin{array}{l}\text { N0. of } \\
\text { image } \\
\text { s }\end{array}$ & 409 & 461 & 377 & 19 \\
\hline $\begin{array}{l}\text { Area } \\
\text { covere } \\
\text { d }\end{array}$ & $0.0033 \mathrm{~km}^{2}$ & $0.0029 \mathrm{~km}^{2}$ & $0.0018 \mathrm{~km}^{2}$ & $0.0035 \mathrm{k}$ \\
\hline $\begin{array}{l}\text { Avera } \\
\text { ge } \\
\text { densit } \\
\mathrm{y}\left(\mathrm{m}^{3}\right)\end{array}$ & 12646 & 21118.3 & 25141.3 & 14089.7 \\
\hline
\end{tabular}

Table 3. Procedure for the four Weekly Surveys

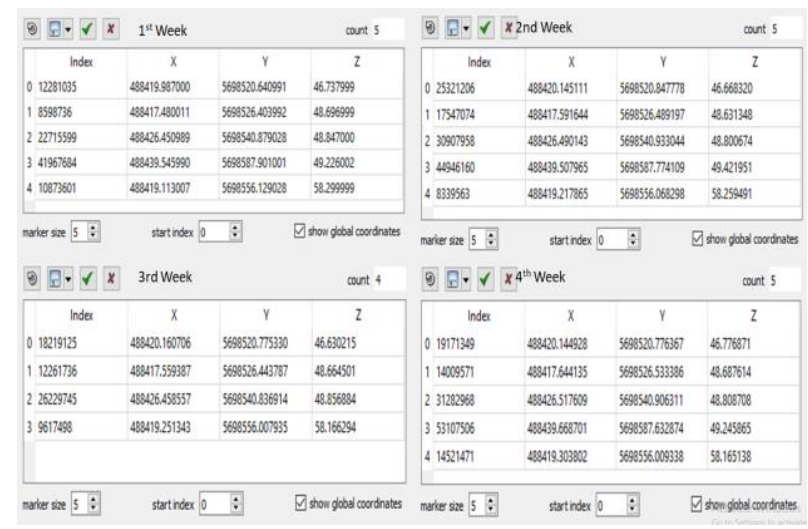

Figure 10. Geographical Coordinates of all four Weekly Surveys in CloudCompare

\begin{tabular}{|l|c|l|l|l|l|l|}
\hline & \multicolumn{2}{|c|}{ Wk 1 -WK 2 } & \multicolumn{2}{c|}{ Wk 1 -WK 3 } & \multicolumn{2}{c|}{ Wk 1 -WK 4 } \\
\hline & $\Delta \mathbf{N}$ & $\Delta \mathbf{E}$ & \multicolumn{1}{|c|}{$\Delta \mathbf{N}$} & $\Delta \mathbf{E}$ & \multicolumn{1}{|c|}{$\Delta \mathbf{N}$} & $\Delta \mathbf{E}$ \\
\hline Pt.1 & - & - & - & - & - & - \\
& 0.158 & 0.206 & 0.173 & 0.13 & 0.157 & 0.13 \\
& 111 & 787 & 706 & 4339 & 928 & 537 \\
& & & & & & 6 \\
\hline Pt.2 & - & - & - & - & - & - \\
& 0.111 & 0.085 & 0.079 & 0.03 & 0.164 & 0.12 \\
& 633 & 205 & 376 & 9795 & 124 & 939 \\
\hline Pt. 3 & - & - & - & 0.04 & - & - \\
& 0.039 & 0.054 & 0.007 & 2114 & 0.066 & 0.02 \\
& 154 & 016 & 568 & & 62 & 728 \\
\hline Pt. 4 & 0,038 & 0.126 & - & 0.12 & - & 0.20 \\
& 025 & 892 & 0.138 & 1093 & 0.122 & 813 \\
& & \multicolumn{7}{|c}{} \\
\hline
\end{tabular}

\begin{tabular}{|c|c|l|l|l|l|l|}
\hline Pt. 5 & - & 0.060 & & & - & 0.11 \\
& 0.104 & 73 & & & 0.190 & 969 \\
& 858 & & & & 795 & \\
\hline
\end{tabular}

Table 4. Accuracies of all four Weekly Surveys

The standard deviation for "alignment and surface deviation" (Westoby et al, 2018) at every point on each point cloud is \pm $0.05 \mathrm{~m}$ in the Northing and $\pm 0.12 \mathrm{~m}$ on the Easting's for the selfcalibrated digital camera and without the use of GNSS control points. This shows that each of the point cloud models geometrically fits into the other for a second-order cliff monitoring deformation study (Westoby et al, 2018 and Ruzic et al, 2015).

\subsection{Verifying the Correctness of the CloudCompare Global Coordinates}

To verify the correctness of the CloudCompare coordinates, the DSM of one of the Pole Survey Point Cloud (PSPC) was imported into ArcMap and the coordinates of the control points in CloudCompare as in Figure 10 is found to be the same as in ArcMap.

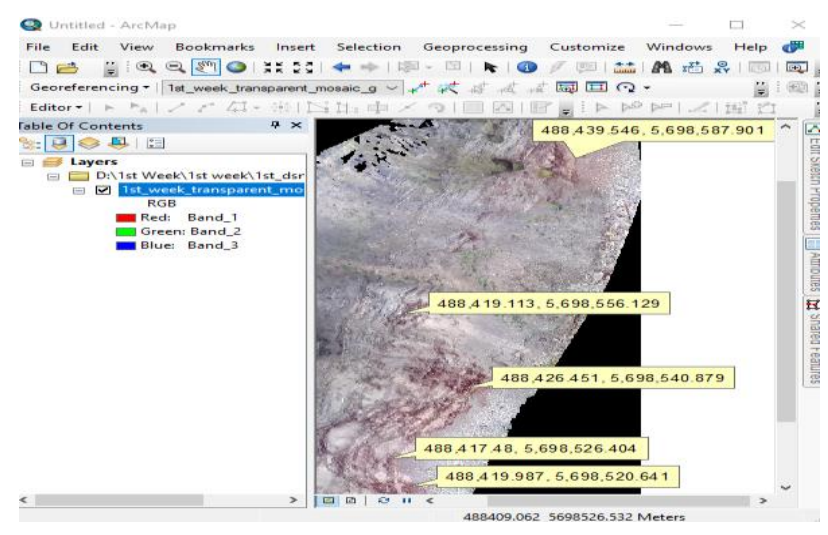

Figure 11. Verification of the CloudCompare Global Coordinates in ArcMap

The geometric accuracy defines the comparative evaluation with datasets obtained from other reliable photogrammetric techniques while the absolute accuracy is the difference of the $\mathrm{x}, \mathrm{y}$, and $\mathrm{z}$ coordinates of every point on the point cloud to their true geographical position on ground (Harwin and Lucieer, 2012). The 3D reconstruction process in the bundle adjustment may distort the original shape of the cliff surface alignment.

The TLS and the Pole survey were both used to survey the same stretch of the cliff surface on the $13^{\text {th }}$ of March 2020. This is to be able to determine the global correctness of the digital image EXIF and structure from motion computation for bundle adjustment that optimizes the 3D location between the tie-points and the camera internal parameters (Turner et al, 2012).

The TLS survey was using the Topcon Laser scanner GLS$2000 \mathrm{M}$ series. The 8.9-degree telephoto camera provided the complete stereoscopic coverage of the cliff surface at $6.3 \mathrm{~mm}$ at $10 \mathrm{~m}$ resolution. Two different prism scan locations provided the precise and accurate modelling of the cliff section monitored. The fixed pole at (window scanning) enhances accuracies although it takes longer to scan but reduces the registration of the point cloud in the Topcon ScanMaster software. The height of the pole for this survey was $2 \mathrm{~m}$ and the prisms are $125 \mathrm{~mm}$. Georeferencing was by the GEOMAX Zenith 35 series on Real-Time Kinematic (RTK) mode. 


\subsection{Control Points for Georeferencing the Pole Survey}

Four markers at the bottom of the cliff with other visible points on both surveys in the middle of the inaccessible clifftop were used as manual tie-points for geolocating the pole survey in Pix4D on OSGB 1936 coordinate system as shown in figure 12 below.

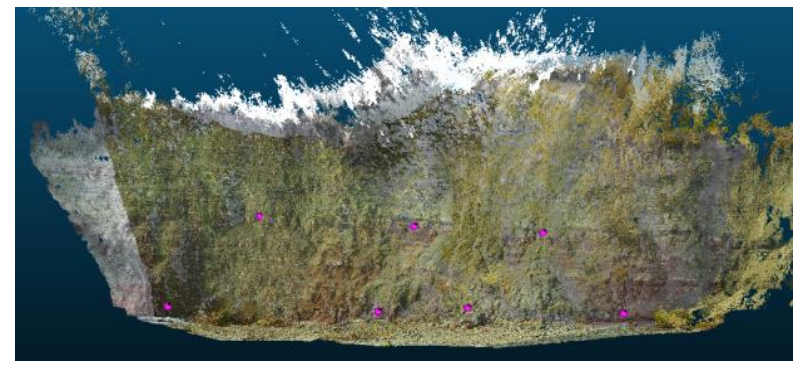

Figure 12. Control Points for Geolocating the Pole Survey

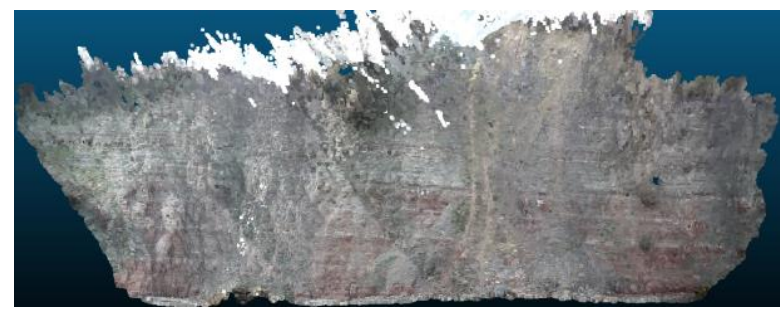

Figure 13. Pole Survey Point Cloud

The $\mathrm{X}, \mathrm{Y}$, and $\mathrm{Z}$ coordinates of some points at the top, sides, and at the bottom of the pole and TLS point clouds, read off, and compared in CloudCompare as shown in figure 15 and table 5 below.

\begin{tabular}{|c|c|c|c|c|c|c|c|}
\hline (8) $=\sqrt{x}$ & & IS & cont 5 & (2) $D x$ & & ek 6 & want 5 \\
\hline Inder & $x$ & $\gamma$ & 2 & Inder & $x$ & y & l \\
\hline 0213243 & 3190650.550597 & 171640457336 & 8996500 & 04130080 & 31966158876 & 171620400602 & 9003666 \\
\hline 1 107356 & 3190:4795:57 & 171666657288 & 8817200 & 12001430 & 31951783226 & 1776566560535 & 884731 \\
\hline 248178 & 31044405555 & 1716404041355 & 96120200 & 29115833 & 319046252333 & 17664028590 & 962068 \\
\hline 3 4361441 & 319066283598 & 17162335131318 & 90,1600 & 3 301515 & 319062822272 & 17162336782 & 90828601 \\
\hline $41242 \pi 3$ & 31902552057 & 1716337.76334 & 20022599 & 4 190003:4 & 3190516358512 & 17163313727 & 20.82879 \\
\hline rater sae 5 : & statindex [ & $\vdots$ & D son gobal corden & makes sie 5 : & statinex 0 & : & 7 stow gobd covoridtes \\
\hline
\end{tabular}

Figure 15. Example of Coordinates of TLS and Pole Survey in CloudCompare

Table 5. Differences in the Coordinates of some Points in the TLS and Pole Surveys

\begin{tabular}{|l|c|c|c|}
\hline & \multicolumn{3}{|c|}{ TLS - Week 6 } \\
\hline & $\Delta \mathbf{N}$ & $\Delta \mathbf{E}$ & $\Delta \mathbf{Z}$ \\
\hline Point1 & -0.008 & 0.053 & -0.035 \\
\hline Point 2 & 0.017 & 0.001 & -0.030 \\
\hline Point 3 & -0.034 & 0.013 & -0.008 \\
\hline Point 4 & 0.002 & 0.024 & -0.071 \\
\hline Point 5 & -0.045 & 0.030 & -0.030 \\
\hline
\end{tabular}

The maximum deviation in the XYZ coordinates of the PSPC at every point as compared with the TLSPC is $5 \mathrm{~cm}$.

The accuracies of the geometry of the PSPC and the TLSPC are subject to further scrutiny by creating their contours using the triangulation and the linear interpolation gridding method in the Surfer Golden Software (Sufer, 2018). The triangulation with linear interpolation uses the anisotropy to determine its contour (Bayazit, 2019). Anisotropy is dependent on the direction irrespective of the properties of the surface materials will generate an unbiased contour interpretation (Bayazit, 2019). The choice to use the multiple refractive indexes is due to the irregular surface nature of the cliff that has the capabilities for change in direction within the shortest possible period resulting from falls and collapse.
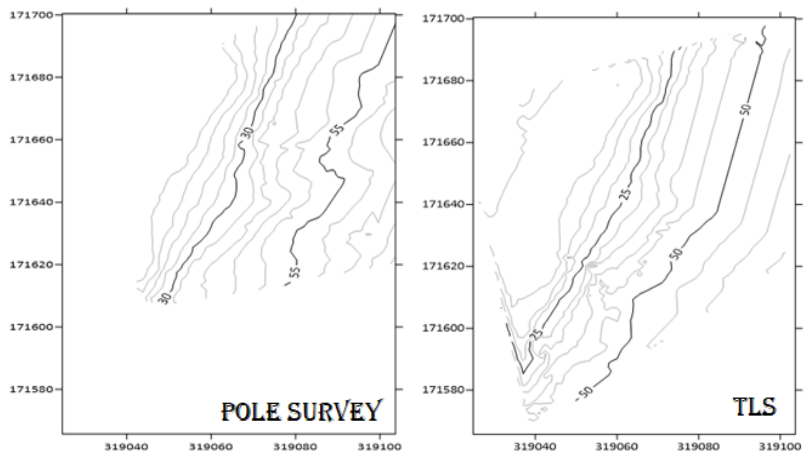

Figure 16. PSPC and TLSPC Contours generated in Suffer Golden Software

\section{DISCUSSION OF RESULTS}

\subsection{Visual Comparison with Other Datasets}

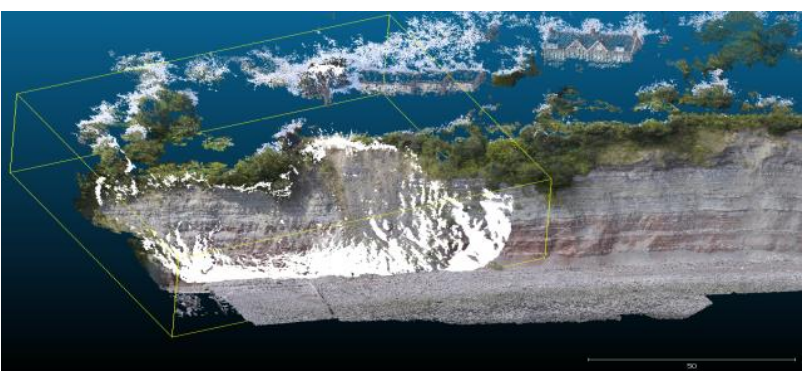

Figure 17. Pole Survey (on white) Superimposed on an Equivalength Drone Survey

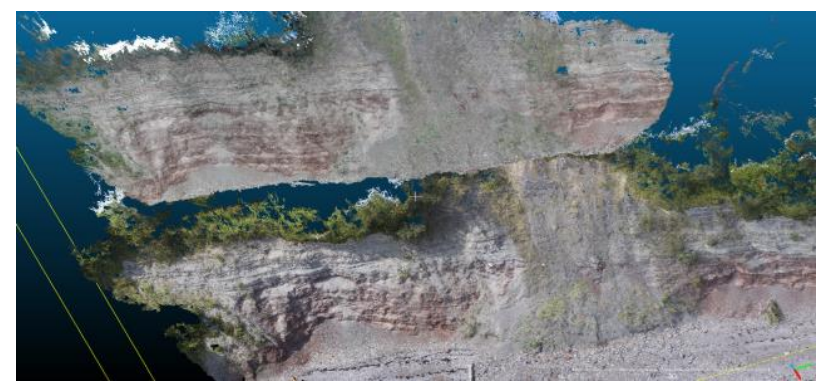

Figure 18. Like-to-like Alignment (Pole Survey up and Drone Survey down) 


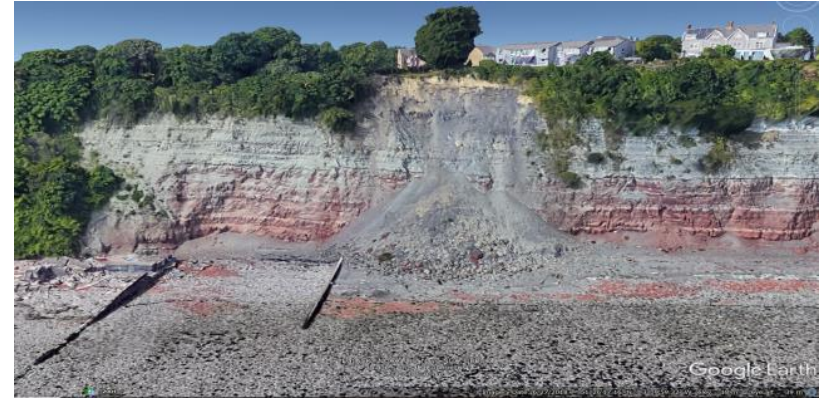

Figure 19. 2018 Google Earth Imagery of the Study Area
Recent studies show that the $\mathrm{M} 3 \mathrm{C} 2$ will be more effective for comparing irregular surfaces like the cliff (Lague et al, 2013). This is because the algorithm distance computation is not dependent on the spatial correlation and the dimensional orientation between the surfaces (Esposito et al, 2017).

In figure 20 below, the $\mathrm{M} 3 \mathrm{C} 2$ in the open-source Cloudcompare is used to perform change analysis between four weekly surveys. The evaluation of the detectable surface changes is at a minimum of $\pm 6 \mathrm{~mm}$. From week 1 to 2 , the fuller Earth is obvious and completely erodes from week 4 to week 5 . There are insignificant changes from week 2 to week 3 and complete cliff erosion at points a. b, c, d, e, f, g, h, I.

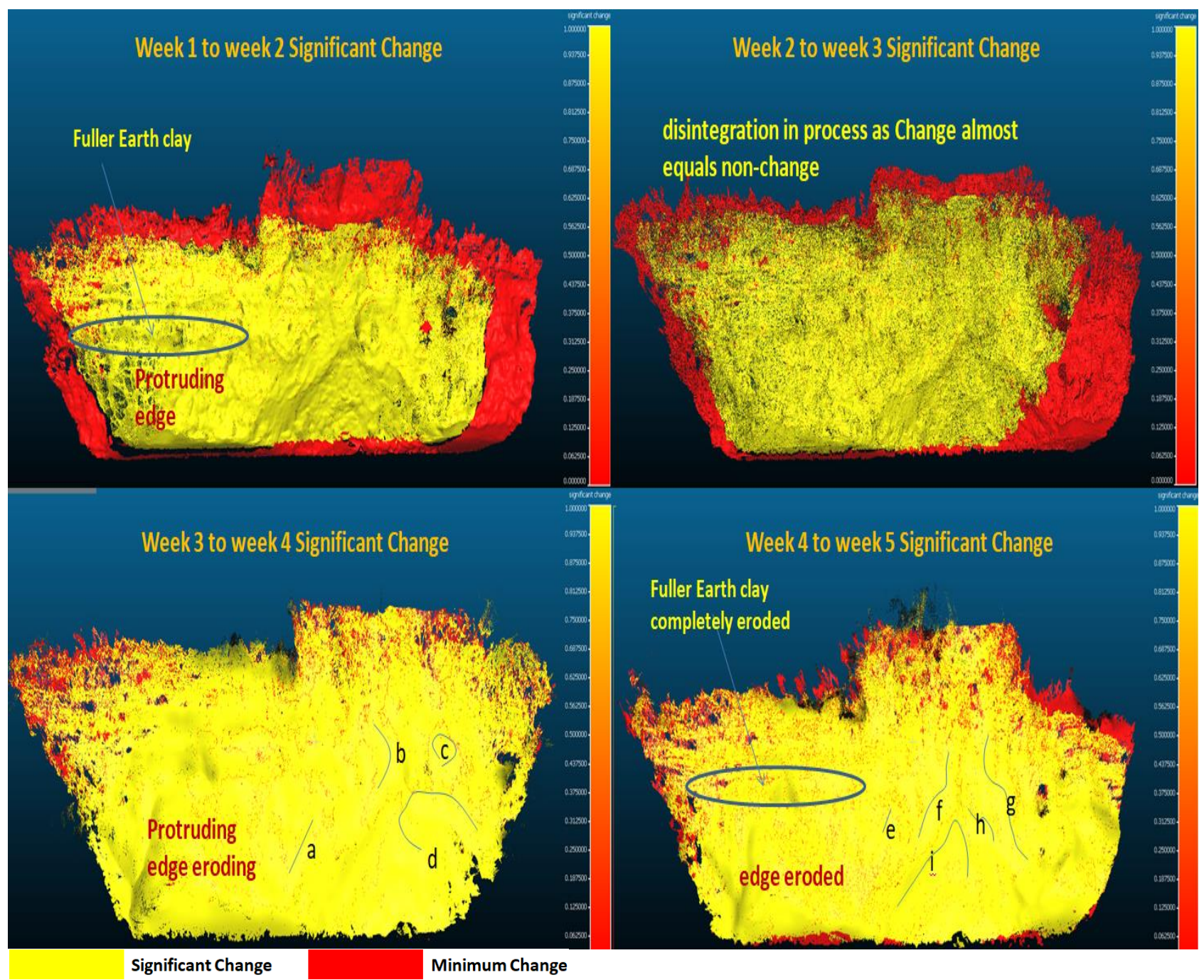

Figure 20. Explains the significant changes between four weekly surveys at $6 \mathrm{~mm}$ detectable surface change.

\section{CONCLUSION}

The contribution to knowledge is a new pole digital photogrammetry methodology for coastal cliff monitoring. This research utilizes the very basic principles of photogrammetry in developing a systematic flight plan and camera orientation to able to generate precise and accurate 3D reconstructed point cloud by terrestrial pole survey for coastal cliff monitoring. The methodology developed is simple, straightforward with a regular grid network for complete stereoscopic coverage. The verification of results obtained has been by third-party software and an alternative remote sensing survey.

This methodology generates precise geometrical related point clouds with or without the GNSS controls. For use in the photogrammetry community, the most appropriate vertical camera inclination and distance to the cliff surface has been practically demonstrated and theoretically documented. 
Depending on the area been mapped, surveys can be from 10 minutes to 2 hours. It is possible to attach the different digital cameras on the pole with the higher resolution cameras resulting in higher spectral accuracies. The limitation is to perform a survey in an almost equal atmospheric condition to avoid the drifting of the MEMS-IMU during the survey. Surveys performed at a very close range can detect hidden sections/crack on the cliff, but care must be not to change the viewing angle of the digital camera during use. Surveys do not require the drone licence, but care must be not to drop the pole during use.

\section{REFERENCES}

Aber, J. W. and Babb, T. A. (2018) 'The Challenges of Processing Kite Aerial Photography Imagery with Modern Photogrammetry Techniques', International Journal of Aviation, Aeronautics, and Aerospace 5(2) pp. 1-30. IJAAA [Online]. Available at:

https://commons.erau.edu/ijaaa/vol5/iss2/2/ (Accessed: 25 March 2019).

Bayazit, U. (2019) 'A Greedy Region Growing Algorithm for Anisotropic Stretch Adaptive Triangulation of Geometry Images', Graphical Models 106(101045) pp. 1524-0703. ScienceDirect [Online]. Available at:

https://www.sciencedirect.com/science/article/pii/S152407031 9300360 (Accessed: 13 June 2020).

Benassi, F., Dall'Asta, E., Diotri, F., Forlani, G., Morra di Cella, U., Roncella, R. and Santise, M. (2017) 'Testing Accuracy and Repeatability of UAV Blocks Oriented with GNSS-Supported Aerial Triangulation', Remote Sensing 9(2) pp. 2-23. MDPI [Online]. Available at:

https://www.mdpi.com/2072-4292/9/2/172 (Accessed: 11 December 2017).

Carter, N., Hashemian, A., Mckelvey, N. (2019) 'An Optimization of Small Unmanned Aerial System (sUAS) Image Based Scanning Techniques for Mapping Accident Sites', SAE Technical Paper 2019-01-0427.SAE Mobilus [Online]. Available at: https://saemobilus.sae.org/content/2019-01-0427/ (Accessed: 11 September 2019).

Colomina, I. and Molina, P. (2014) 'Unmanned aerial systems for photogrammetry and remote sensing: A review', ISPRS Journal of Photogrammetry and Remote Sensing 92, pp. 7997. Science Direct [Online]. Available at: http://www.sciencedirect.com/science/article/pii/S0924271614 000501(Accessed: 25 May 2016)

Constable, C. (2016) 'Earth's Electromagnetic Environment', Surveys in Geophysics 37(1) pp. 27-45. Springer [Online]. Available at: https://link.springer.com/article/10.1007/s10712015-9351-1 (Accessed: 03 October 2019).

Cwiakala, P., Kocierz, R., Puniach, E., Nedzka, M., Mamczarz, K., Niewiem, W. and Wiacek, P. (2018) 'Assessment of the Possibility of Using Unmanned Aerial Vehicles (UAVs) for the Documentation of Hiking Trails in Alpine Areas', Sensors 18(1) pp. 2-28. NCBI [Online]. Available at: https://www.ncbi.nlm.nih.gov/pmc/articles/PMC5795845/ (Accessed: 02 July 2019).
Dai, F., Feng, Y. and Hough, R. (2014) 'Photogrammetric Error Sources and Impacts on Modelling and Surveying in Construction Engineering Applications', Visualization in Engineering 2(2) pp. 2-14. Springer [Online]. Available at: https://link.springer.com/content/pdf/10.1186\%2F2213-7459-22.pdf (Accessed: 17 December 2018). 04017008-1 - 0401700821.

Earlie, C., Masselink, G. and Russel, P. (2017) 'The Role of Beach Morphology on Coastal Cliff Erosion Under Extreme Waves', Earth Surface Processes and Landforms 43(6) pp. 1213-1228. Wiley Library [Online]. Available at: https://onlinelibrary.wiley.com/doi/full/10.1002/esp.4308 (Accessed: 15 February 2018).

Esposito, G., Salvini, R., Matano, F., Sacchi, M., Danzi, M., Somma, R. and Troise, C. (2017) 'Multitemporal Monitoring of a Coastal Landslide through SFM-Derieved Point Cloud Comparison', The Photogrammetric Record 32(160) pp. 459479. Ingenta Connect [Pnline]. Available at:

https://www.ingentaconnect.com/content/asprs/pers/2010/00000 076/00000010/art00001; jsessionid=2b0icttstd7nn.x-ic-live-02\# (Accessed 11 July 2020).

Galea, P., Amico, S. D. and Farrugia, D. (2014) 'Dynamic Characteristics of an Active Coastal Spreading Area Using Ambient Noise Measurements - Anchor Bay, Malta', Geophysical Journal International 199(2) pp. 1166-1175. IEEE Xplore [Online]. Available at: https://ieeexplore.iee.org/document/8205841 (Accessed: 17 November 2017).

Harwin, S. and Lucieer, A. (2012) 'Assessing the Accuracy of Georeferenced Point Clouds Produced Via Multi-View Stereopsis from Unmanned Aerial Vehicle (UAV) Imagery', Remote Sensing 4(6) pp. 1573-1599. MDPI [Online]. Available at: http://www.mdpi.com/2072-4292/4/6/1573 (Accessed: 19 October 2016).

Huang, S., Zhang, Z., Ke, T., Tang, M. and Xu, X. (2015) 'Scanning Photogrammetry for Measuring Large Targets in Close Range', Remote Sensing 7(8) pp. 10042-10077. MDPI [Online]. Available at: https://www.mdpi.com/20724292/7/8/10042/htm (Accessed: 08 February 2019).

James, M. R. and Robson, S. (2014) 'Mitigating Systematic Error in Topographic Models Derived from UAV and GroundBased Image Networks', Earth Surface Processes and Landforms 39(10) pp. 1413-1420. Wiley Library [Online]. Available at:

https://onlinelibrary.wiley.com/doi/full/10.1002/esp.3609 (Accessed 07 February 2019).

Juad, M., Passot, S., Bivic, R. L., Delacourt, C., Grandjean, P. and Dantec, N. L. (2016) 'Assessing the Accuracy of HighResolution Digital Surface Models Computed by PhotoSCan and MicMac in Sub-Optimal Survey Conditions', Remote Sensing 8(6), 465; pp. 2-18. MDPI [Online]. Available at: http://www.mdpi.com/2072-4292/8/6/465 (Accessed: 26 May 2018).

Karaim, M., Elsheikh, M. and Noureldin, A. (2018) 'GPS GNSS Error Sources' inRustamov, R. B. and Hashimov, A. M. (eds), Multifunctional Operation and Application of GPS, IntechOpen, pp. 69-85. Available at:

https://www.intechopen.com/books/multifunctional-operation- 
and-application-of-gps/gnss-error-sources (Accessed: 03 October 2019).

Kromer, R. A., Abellan, A., Hutchinson, D. J., Lato, M., Edwards, T. and Jaboyedoff, M. (2015) A 4D Filtering and Calibration Techniques for Small-Scale Point Cloud Change Detection with a Terrestrial Laser Scanner, Remote Sensing 7(2) pp. 13029-13052. MDPI [Online]. Available at: https://www.mdpi.com/2072-4292/7/10/13029 (Accessed: 06July 2020).

Lague, D., Brodu, N. and Leroux, J. (2013) 'Accurate 3D Comparison of Complex Topography with Terrestrial Laser Scanner: Applications to the Rangitikei Canyon (N-Z)', ISPRS Journal of Photogrammetry and Remote Sensing 82 pp. 10-26. Science Direct [Online]. Available at: https://www.sciencedirect.com/science/article/abs/pii/S092427 1613001184 (Accessed: 24 November 2017).

Letortu, P., Juad, M., Grandjean, P., Ammann, J., Costa, S., Maquaire, O., Davidson, R., Dantec, N. L. and Delacourt, C. (2018) 'Examining High-Resolution Survey Methods for Monitoring Cliff Erosion at an Operational Scale', Behavioural Science and Public Health Titles 55(4) pp. 457476. Hal. Archives [Online]. Available at: https://hal.archivesouvertes.fr/hal-01647588/document (Accessed: 31 August 2018).

Liu, S., Zhu, W., Zhang, C. and Sun, W. (2016) ‘3D Reconstruction of Indoor Scenes Using RGB-D Monocular Vision', International Conference on Robots and Intelligent System (ICRIS), Zhangjiajie, China, 27-28 August. IEEE Xplore [Online]. Available at:

https://ieeexplore.ieee.org/abstract/document/7757064/authors \#authors (Accessed: 10 September 2019).

Mancini, F., Castagnetti, C., Rossi, P., Dubbini, M., Fazio, N, L., Perrotti, M. and Lollino, P. (2017) 'An Integrated Procedure to Assess the Stability of Coastal Rocky Cliffs: From UAV Close-Range Photogrammetry to Geomechanical Finite Element Modelling', Remote Sensing (9)12 pp. 2-21. MDPI [Online]. Available at: https://www.mdpi.com/20724292/9/12/1235 (Accessed: 30 January 2019).

Masiero, A., Fissore, F. and Vettore, A. (2017) 'A Low Cost UWB Based Solutions for Direct Georeferencing UAV Photogrammetry', Remote Sensing 9(5) pp. 2-21. MDPI [Online]. Available at: https://www.mdpi.com/20724292/9/5/414 (Accessed: 27 March 2019).

Nesbit, P. R. and Hugenholtz, C. H. (2019) 'Enhancing UAVSFM 3D Model Accuracy in High-Relief Landscapes by Incorporating Oblique Images', Remote Sensing 11(3) pp. 224. MDPI[Online]. Available at: https://www.mdpi.com/20724292/11/3/239/htm (Accessed: 17th June 2019).

Perez-Alberti, A. and Trenhaile, A. S. (2014) 'An Initial Evaluation of Drone-Based Monitoring of Boulder Beaches in Galicia, North-Western Spain', Earth Surface Processes and Landforms 40(1) pp. 105-111. Wiley Library [Online]. Available

https://onlinelibrary.wiley.com/doi/full/10.1002/esp.3654 (Accessed: 27 March 2019).

Pepe, M., Fregonese, L. and Scaioni, M. (2018) 'Planning Airborne Photogrammetry and Remote- Sensing Missions with Modern Platforms and Sensors', European Journal of
Remote Sensing 51(1) pp. 412-436. TandF [Online]. Available at:

https://www.tandfonline.com/doi/full/10.1080/22797254.2018.1 444945 (Accessed: 04 October 2019).

Qu, Y., Huang, J. and Zhang, X. (2018) 'Rapid 3D Reconstruction for Image Sequence Acquired from UAV Camera', Sensors 18(1):225 pp. 2-20. NCBI [Online]. Available at: https://www.ncbi.nlm.nih.gov/pmc/articles/PMC5795716/ (Accessed: 11 May 2018).

Rau, J. Y., Habib, A. F., Kersting, A. P., Chiang, K. W., Bang, K. I., Tseng, Y. H. and Li, Y. H. (2011),'Direct Sensor Orientation of a Land-Based Mobile Mapping System', Sensors 11(7) pp. 7243-7261. NCBI [Online]. Available at: https://www.ncbi.nlm.nih.gov/pmc/articles/PMC3231683/ (Accessed: 23 January 2019).

Roncella, R., Forlani, G., Fornari, M. and Diotri, F. F. (2014) 'Landslide Monitoring by Fixed-Based Terrestrial StereoPhotogrammetry', ISPRS Technical Commission V Symposium, Riva Del Garda, Italy, 23-25 June. ISPRS Annals of the Photogrammetry, Remote Sensing and Spatial InformationSciences, Volume 11-15. ISPRS [Online]. Available at: https://www.isprs-ann-photogramm-remote-sens-spatial-infsci.net/II-5/297/2014/isprsannals-II-5-297-2014.pdf (Accessed: 08 February 2019).

Ruzic, I., Benac, C., Marovic, I. and IIic, S. (2015) 'A Stability Assessment of Coastal Cliffs Using Digital Imagery', Acta GeotechnicaSlovenica 12(2) pp. 25-35. Digital Library of University of Maribor [Online]. Available at: https://dk.um.si//zpisGradiva.php?id=70850\&lang=eng (Accessed: 24 January 2019).

Ruzgiene, B., Berteska, T., Gecyte, S., Jakubauskiene, E. and Aksamitauskas, C. V. (2015) 'The Surface Modelling Based on UAV Photogrammetry and Qualitative Estimation',

Measurement 73 pp. 619-627. ScienceDirect [Online]. Available at:

https://www.sciencedirect.com/science/article/pii/S0263224115 002316 (Accessed: 24 January 2019).

Sciarra, N., Marchetti, D., Avanzi, G. D. and Calista, M. (2014) 'Rock Slope Analysis on the Complex Livorno Coastal Cliff (Tuscany, Italy)', GFDQ 37 pp. 113-130. GFDQ [Online]. Available at: http://gfdq.glaciologia.it/037_2_04_2014/ (Accessed: 24 January 2019).

Singh, P. K., Kainthola, A., Panthee, S. and Singh, T. N. (2016) 'Rockfall Analysis Along Transportation Corridors in High Hill Slopes', Environmental Earth Sciences 75(5) pp. 1-11. Springer Link [Online]. Available at:

https://link.springer.com/article/10.1007/s12665-016-5489-

5\#citeas(Accessed: 06 September 2019).

Somma, R., Matano, F., Marino, E., Caputo, T., Esposito, G., Caccavale, M., Carlino, S., Luliano, S., Mazzola, S., Molisso, F., Sacchi, M., Troise, C. and Natale, G. D. (2015) 'Application of LaserScanning for Monitoring Coastal Cliff Instability in the Pozzuoli Bay, Coroglio Site, PosillipoHill,Naples', Engineering Geology for Society and Territory 5 pp. 687-690. Springer Link [Online]. Available at: https://link.springer.com/chapter/10.1007/978-3-319-090481_133 (Accessed: 31 October 2017). 
Surfer (2014) Contouring, Gridding and 3D Surface Mapping Available at: https://www.goldensoftware.com/ (Accessed: 13 June 2020).

Terefenko, P., Wziatek, D. Z., Dalyot, S., Boski, T. and LimaFilho, F. P. (2018) 'A High -Precision LiDAR-Based Methods for Surveying and Classifying Coastal Notches', International Journal of Geo-Information 7(8) pp. 2-16. MDPI [Online]. Available at: https://www.mdpi.com/2220-9964/7/8/295 (Accessed: 08 February 2019).

Turner, D., Lucieer, A. and Jong, S. M. D. (2015) 'Time Series Analysis of Landslide Dynamics Using an Unmanned Aerial Vehicle (UAV)', Remote Sensing 7(2) pp. 1736-1757. MDPI [Online]. Available at: https://www.mdpi.com/20724292/7/2/1736/htm (Accessed: 24 January 2019).

Turner, D., Lucieer, A. and Watson, C. (2012) 'An Automated Technique for Generating Mosaics from Ultra-High Resolution Unmanned Aerial Vehicle (UAV) Imagery, Based on Structure from Motion (SFM) Point Clouds', Remote Sensing 4(5) pp. 1392-1410. MDPI [Online]. Available at: https://www.mdpi.com/2072-4292/4/5/1392/htm (Accessed: 05 June 2020).

Tziavou, O., Pytharouli, S. and Souter, J. (2018) 'Unmanned Aerial Vehicle (UAV) Based Mapping in Engineering Geological Surveys: Considerations for Optimum Results', Engineering Geology 232() pp. 12-21. ScienceDirect [Online]. Available at: https://www.sciencedirect.com/science/article/abs/pii/S001379 5217308670 (Accessed: 08 September 2019).

Varela, M. R., Patricio, A. R., Anderson, K., Broderick, A. C., DeBell, L., Hawkes, L. A., Tilley, D., Snape, R. T. E., Westoby, M. J. and Godley, B. J. (2019) 'Assessing Climate Change Associated Sea-Level Rise Impacts on Sea Turtle Nesting Beaches Using Drones, Photogrammetry and a Novel GPS System', Global Change Biology 25(2) pp. 753-762. Wiley Library [Online]. Available at: https://onlinelibrary.wiley.com/doi/abs/10.1111/gcb.14526 (Accessed 16 April 2019).

Westoby, M. J., Dunning, S. A., Woodward, J., Hein, A. S., Marrero, S. M., Winter, K. and Sugden, D. E. (2015) 'Sedimentological Characterization of Antarctic Moraines Using UAVs and Strcture-from-Motion Photogrammetry', Journal of Glaciology 61(230) pp. 1088-1102. IGS [Online]. Available at: https://www.igsoc.org/ (Accessed: 01 September 2019).

Westoby, M. J., Lim, M., Hogg, M., Pound, M. J., Dunlop, L. and Woodward, J. (2018) 'Cost-Effective Erosion Monitoring of Coastal Cliffs', Coastal Engineering 138 pp. 152-164. ScienceDirect [Online]. Available at: https://www.sciencedirect.com/science/article/pii/S037838391 7303381 (Accessed: 25 August 2018).

Xu, G., Zheng, A., Li, X. and Su, J. (2017) 'Position and Orientation Measurement Adopting Camera Calibration by Projection Geometry of Plucker Matrices of ThreeDimensional Lines', Scientific Reports 7(44092) pp. 1-10. Scientific Report [Online]. Available at:

https://www.nature.com/articles/srep44092 (Accessed: 10 September 2019).
Young, A. P., Guza, R. T., O'Reilly, W. C., Burvingt, O. and Flick, R. E. (2016) 'Observations of Coastal Cliff Base Waves, Sand Levels, and Cliff Top Shaking', Earth Surface Processes and Landforms 41 pp. 1564-1573. Wiley [Online]. Available at: https://onlinelibrary.wiley.com/doi/full/10.1002/esp.3928 (Accessed: 08 February 2019).

Yu, C., Zhenhong, L. and Penna, N. T. (2018) 'Interferometric Synthetic Aperture Radar Atmospheric Correction Using a GPS-Based Iterative Tropospheric Decomposition Model', Remote Sensing of Environment 204 pp. 109-121. Science Direct [Online]. Available at: https://www.sciencedirect.com/science/article/pii/S0034425717 305011 (Accessed: 04 April 2019).

Zhang, Z., Pan, S., Gao, C., Zhao, T. and Gao, W. (2019) 'Support Vector Machine for Regional Ionospheric Delay Modelling', Sensors 19(13) pp. 1-14. MDPI [Online]. Available at: https://www.mdpi.com/1424-8220/19/13/2947 (Accessed: 03 October 2019).

Zhu, B., Li, J. and Tang, W. (2017) 'Correcting Insar Topographically Correlated Tropospheric Delays Using a Power Law Model Based on ERA-Interim Reanalysis', Remote Sensing 9(8) pp. 1-23. MDPI [Online]. Available at: https://www.mdpi.com/2072-4292/9/8/765 (Accessed: 04 October 2019). 